\title{
Offshore Outsourcing Teacher Inservice Education: The Long-Term Effects of a Four-Month Pedagogical Program on Japanese Teachers of English
}

This longitudinal study tracked five public junior and senior high school Japanese teachers of English (JTEs) who were sponsored by the Japanese Ministry of Education, Culture, Sports, Science and Technology (MEXT) to study English and Communicative Language Teaching (CLT) pedagogy at a host university in Canada. This qualitative case study found that teachers who were not bound by practical constraints such as grammar-based entrance examinations or external influences such as a perceived need to conform to the practices of colleagues were able to incorporate what they had learned in Canada. However, high school teachers facing these constraints tended to abandon new practices in favor of traditional teaching methods such as grammar translation. These findings suggest that JTEs do benefit from overseas study, but that the extent of what they can incorporate into their regular teaching practice depends on the context in which they teach. The findings imply that host program planners and instructors could benefit from a closer look at constraints faced by third-year public high school teachers in particular, as it is they who face the greater number of obstacles to incorporating CLT into their regular teaching practice.

Cette étude longitudinale a suivi cinq enseignants japonais qui offrent des cours d'anglais au secondaire et qui étaient parrainés par le ministère japonais de l'éducation, la culture, le sport, la science et la technologie pour étudier l'anglais et l'enseignement des langues par l'approche communicative dans une université hôte au Canada. Cette étude de cas qualitative a trouvé que les enseignants qui $n^{\prime} e ́ t a i e n t$ pas liés par des contraintes pratiques comme les examens d'admission basés sur la grammaire ou par des influences externes comme le besoin perçu de se conformer aux pratiques des collègues arrivaient à intégrer ce qu'ils avaient appris au Canada. Toutefois, les enseignants au secondaire confrontés à ces contraintes ont tendance à abandonner les nouvelles pratiques en faveur des méthodes traditionnelles d'enseignement telles la traduction de la grammaire. Les résultats portent à croire que les enseignants japonais d'anglais profitent effectivement des études outremer, mais l'intégration qu'ils en font dans leur pratique régulière dépend du contexte dans lequel ils enseignent. Ces constatations laissent entendre que les planificateurs de programmes d'accueil et les instructeurs pourraient profiter d'un examen plus poussé des contraintes auxquelles font face 
les enseignants, particulièrement ceux au secondaire 3 dans les écoles publiques car c'est eux qui affrontent le plus d'obstacles dans l'intégration de l'approche communicative dans leur pratique pédagogique régulière.

\section{Introduction}

As part of its mandate to "cultivate Japanese with English abilities" (Ministry of Education, 2003), the Japanese Ministry of Education, Culture, Sports, Science and Technology (MEXT) has been sponsoring Japanese junior and senior high school teachers of English (JTEs) to study English-language and Communicative Language Teaching (CLT) pedagogy in English-medium countries such as the United Kingdom, the United States, and Canada. Research on these programs (Kurihara \& Samimy, 2007; Lamie, 2001; Pacek, 1996) has found that although JTEs' beliefs and to some degree practices may have changed, a number of constraints continue to limit their ability to incorporate CLT into their regular teaching practice. These include personal and practical constraints, as well as external influences, lack of awareness of CLT, and a lack of teacher training.

Practical constraints-those regarding curricular and instructional issues (Lamie, 2001)—were cited the most often by JTEs as barriers to implementing CLT. These included entrance examination preparation pressures; resistance from students, parents, and colleagues; the requirement to use Ministrymandated textbooks; and institutional culture, beliefs, and practices. Although studies span a 10-year period (Kurihara \& Samimy, 2007; Lamie; Pacek, 1996), it is notable that the same constraints are repeatedly listed. In order to help program planners and host instructors better understand why, it may be useful to take a closer look at language-teacher training in Japan; the interrelated constraints of entrance examinations, mandatory textbooks, and the persistence of the grammar translation method; and finally, the daily realities of Japanese teachers of English as reflected in a lack of time and autonomy.

\section{Teacher Training in Japan}

General certification. In Japan, teacher education, or rather a lack of it, may be one reason why teachers are constrained from incorporating CLT methods into their teaching practice. Although certification of teachers in Japan is carried out by various institutions and is more complex than in Canada, it is relatively easy to become a teacher in Japan. In Canada, in order to become teachers, students already possessing a bachelor's degree enter faculties of education to study pedagogy and partake in extended practica. However, in Japan, most teachers receive certification as part of their bachelor's studies, do not study in faculties of education, and participate in practica ranging from only two to four weeks (Hawley \& Hawley, 1997; Sato \& Asanuma, 2000). After having obtained the Japanese equivalent of a BA or BEd, 
prospective teachers take a two-part Teacher Employment Selection Test. The written test, according to Yonesaka (1999), contains questions designed to test not only candidates' general educational and subject area knowledge, but also their persistence and fortitude. The oral qualification exam may consist of an individual interview in Japanese; again, candidates not only must demonstrate practical knowledge, but also their personality and demeanor may be evaluated (Yonesaka).

Language teacher training. Language teachers in Japan generally major in English literature or linguistics and are not necessarily required to take courses in second-language acquisition theory, ESL methodology and techniques, or testing (Browne \& Wada, 1998; Lamie, 2000; Nagasawa, 2004; Yonesaka, 1999). Most of the courses in teacher training programs are taught in Japanese, courses are knowledge-based rather than skill-based, and the academic climate "discourages students from speaking English and promotes their mistake phobia" (Nagasawa, p. 283).

It has been suggested (Hawley \& Hawley, 1997) that Japanese universities appear to play a minimal role in the education of teachers at both pre- and inservice periods for several possible reasons: their role is to prepare students for entry into the general job market, there are no incentives for teachers to obtain higher degrees, and the provision of training rests with national and prefectural agencies.

Inservice training. For practicing teachers, inservice training is provided by MEXT and prefectural boards of education; however, such programs are not always successful because they may not require JTEs to use English or may be taught by lecturers advocating theories that do not address local problems (Nagasawa, 2004).

\section{Constraints}

Entrance examinations. Although the population is declining in Japan and many private universities are suffering from a shortage of students, and although there are other means of entering universities such as recommendations by high school principals (Kamiya, 2009), most students wishing to enter prestigious national or public universities will have to take university entrance examinations.

In addition to regular schools, many elementary, junior, and senior high school students in Japan attend what may referred to as "parallel," "mirror" (McVeigh, 2002, p. 92), or "shadow" (McVeigh, 2006, p. 172) educational institutions such as juku (cram schools), katei kyoushi (home tutors), and yobiko (preparatory schools). Gakushuu juku in particular are supplementary schools the purpose of which is "explicitly oriented to the ultimate goal of helping ... children do better on entrance examinations" (Rohlen, 1980, pp. 209-210). There students review what is taught in their regular school textbooks such as Japanese, mathematics, English, and science (Blumenthal, 
1992) or are explicitly taught techniques for passing entrance examinations (Tsukada, 1988). Parents send their children to these supplementary institutions with the hope of giving them a competitive edge over their classmates.

However, although one might assume that the presence of juku, katei kyoushi, and yobiko would take pressure off public school teachers and allow them to teach in ways they believe are most beneficial for their students, entrance examinations are said to constrain them as well, because although they wish to teach communicative English, they also feel obliged to help students pass entrance examinations (Sakui, 2004; Sato \& Kleinsasser, 2004). Although an increasing number of students are studying or traveling abroad with a desire to use English as a tool of communication (Yashima, ZenukNishide, \& Shimizu, 2004), entrance examinations may still be one of the strongest and for some students the sole motivation for learning English (Matsumoto, 1994). At present, almost all national and local public universities demand that students wishing to enter them must write the nationwide Center Test, administered by the Education Ministry's College Examination Center (Otsu, 2004). After that, students write in-house tests developed by individual public and private universities. Although a listening component has been added to the Center Examination, there is no oral component; furthermore, university in-house tests contain difficult reading passages and a number of tasks calling for grammar translation (Kikuchi, 2006). Thus teachers may abandon CLT in order to prepare students for the realities of entrance examinations, which despite MEXT's mandate for improved communicative ability do not demand demonstration of communicative proficiency.

Textbooks. Ministry-approved textbooks too are said to constrain teachers because they are obligatory in schools (Gorsuch, 1999). To promote a unified approach, each "comes with a teacher's manual that has detailed lesson plans emphasizing translation and drill-focused teaching techniques" (Browne \& Wada, 1998, p. 105). These lesson plans provide a rigid and formal outline for a class and are often appreciated by teachers who are not confident in English (Langham, 2007) because they do not require additional knowledge and perhaps help those teachers who have not had opportunities to take courses in pedagogy.

Although English courses may be deemed to cover four skills, textbooks tend to focus mainly on reading and writing and to be characterized by a lack of activities that require students to "exchange information, use unscripted language, or to consider English from a larger-than-sentence-level point of view" (Gorsuch, 1999, p. 8). Instead, textbooks tend to present a series of grammatical structures to be analyzed, explained, drilled, and tested (Lamie, 2001). According to Gorsuch, the best way for publishers to sell books is to aim them toward entrance examinations; thus although not communica- 
tively oriented, textbooks may be fulfilling their function of helping students prepare for the realities of entrance examinations.

Grammar translation. As textbooks, in line with entrance examinations, are not communicatively oriented, one traditional method features heavily as the underlying teaching methodology: the Grammar Translation Method or yakudoku, by which many teachers feel constrained. Citing Kawasumi (1975), Hino (1988), explains that "yakudoku is defined as a technique or a mental process for reading a foreign language word-by-word, and the resulting translation reordered to match Japanese word order as part of the process of reading comprehension" (p. 46).

When students are taught to read English, they learn this method and the teachers' aim is to enable students to do it independently. According to Hino (1988), yakudoku is the method of teaching English in Japan. This method persists because it is considered easy by teachers as it requires modest professional training and little preparation is needed for class. Also, because there is little training of EFL teachers, as mentioned above, teachers have tended to teach as they were taught. In addition, Japanese teachers of English do not have to speak English in order to teach using this method (Gorsuch, 2001). Finally, because it is valued as a tool for mental training and shows future employers which people have the dedication and stamina needed in the workplace, it is considered worthwhile (Aspinall, 2003; Beauchamp \& Vardaman, 1994). However, despite its ease of application and integration with both the curriculum and university entrance examinations, some teachers feel constrained by the application of such a methodology. They have a sincere and strong desire to teach communicative English and see the benefits of CLT; yet they abandon these methodologies in order to prepare students for examination success.

Time. In addition to issues related to the curriculum content itself, teachers in Japan report feeling constrained by the time available for them to fulfill their instructional duties. In addition to heavy teaching loads and teaching a five- to six-day workweek, they also work during the summer vacation. According to Okano and Tsuchiya (1999), in 1992, "teachers spent an average of 10 hours 36 minutes a day at school, arriving at school at 7:49 am and leaving at 6:25 pm; and even during the forty-day summer holiday, 44 per cent of teachers spent less than 10 days free at home" (p. 151). Junior high school teachers teach an average of 19.7 hours per week, whereas senior high school teachers teach an average of 16.8 hours per week (Okano \& Tsuchiya, 1999), and in addition, both junior and senior high school teachers are responsible for supervising after-school activities, counseling, and giving supplementary lessons for entrance examinations. Although overworked, many teachers do not take their entitled days off for fear of inconveniencing their colleagues. 
Lack of autonomy. Social and community cultural expectations are not the only issues in relation to time for teachers. Socialization in schools is an influential factor on Japanese teachers' practices generally (Sato \& Kleinsasser, 2004), and teachers who fail to build rapport with colleagues by not conforming to group norms may be faced with "not only an uncomfortable work environment but also a denial of valuable opportunities for professional development" (Okano \& Tsuchiya, 1999, p. 175). With regard to English teaching in particular, research has found that an unwillingness to oppose their colleagues' methods affects teachers' classroom practice, even forcing them to use grammar-translation techniques. Although they may have various beliefs about the best ways to teach English, teachers may be prevented from doing so because of their work environments and in the end, teach what they feel is necessary rather than what they think is right $\left(\mathrm{O}^{\prime}\right.$ Donnell, 2005).

In order to ensure that students are all receiving the same instruction, many schools have specific, set schedules outlining what textbook items should be covered and at what pace. An example of a junior high school syllabus (Department, 2009) details items to be taught to first-year junior high school students during the spring and summer semester from April to August. After an introduction to the textbook, teachers are expected to cover one or two units per month, and the pages they are expected to cover are explicitly stated. These syllabi also stipulate values for, and times of, vocabulary tests, sentence pattern confirmation tests, and listening tests.

In summary, a lack of training in CLT during pre- and post-service training periods, entrance examination demands, mandatory textbooks, traditional methods, and a lack of time and autonomy have been revealed as reasons for JTEs being unable to implement CLT into their regular classroom practice. However, MEXT has been trying to rectify this to some extent by sending JTEs overseas through programs it sponsors and contracts with host universities.

\section{Purpose of the Study}

The goals of past MEXT programs have been to improve JTEs' English proficiency, to expand their knowledge of theory (especially CLT), to expand their repertoire of teaching methods, to improve their understanding of the host culture, and to help them prepare a research paper of 4,000 words on a subject of interest (Kurihara \& Samimy, 2007; Lamie, 2001; Pacek, 1996). The goals of the Canadian MEXT program were similar to these, with what host planners and instructors considered a significant change: the length and focus of the research paper.

According to the program guide from the host Canadian university (the name is not mentioned to ensure anonymity), the primary objective of the program is the promotion of CLT approaches to teaching, the ultimate goal 
being to help Japanese students learn English for communicative purposes. Based on previous experience, and believing that the goal of a final assessment in the format of a 4,000-word essay was too difficult and time-consuming for participants, program planners and instructors at a Canadian host institution renegotiated this assignment with the sponsoring agency, MEXT, and devised a Professional Development Dossier (PDD) instead. The dossier was likened to a tool kit, focusing on each teacher's specific challenges in teaching CLT and containing communicatively oriented activities, either given to or made by JTEs to meet these challenges. The final essay, of a length suitable to the abilities of individual JTEs, would be directly related to their teaching challenges. However, until this time there has been no research into whether introduction of the PDD better enabled JTEs to incorporate CLT into their classroom practice. Conducted over one and a half years, this study aimed to assess the role of this Canadian MEXT program to investigate:

1. Which teachers appeared to be more successful at incorporating new practices into their classes and why;

2. Which teachers appeared to be less successful at incorporating new practices into their classes and why.

\section{Methodology}

This research was part of an observational case study that focused on the four-month pedagogical portion of a six-month program of language and pedagogical study in Canada. This particular study focused on immediate post-program, six-month, and one-year follow-up periods. Data consisted of documents (contracts and lesson plans), questionnaires, observations, and oral interviews based on closed and open-ended questionnaires (Cresswell, 2003; Bogdan \& Biklen, 2007).

The program. While in the MEXT program, in addition to attending classes four mornings a week, JTEs attended lectures by guest speakers, went on field trips, and observed classes at various schools in the city as well as at the host university. As part of their regular course work, they were required to keep reflective teaching journals, prepare poster presentations, visit schools, and observe and teach classes in the university's Intensive English Program. At the end of the program, each participant was required to produce a PDD, which would contain a 20-page essay on an identified critical teaching problem such as incorporating CLT in reading classes or developing speaking activities and a discussion of how CLT could address it; an action file of approaches, lesson plans, and activities to address the teaching problem; a PowerPoint presentation on the same; and a short report on JTEs' perceived improvement in each participant's English-language skill.

With a goal of balancing theory and practice, the host university's fourmonth program consisted of five modules: PDD/Testing and Evaluation (academic writing/presentation skills/testing techniques), Pedagogical 


\begin{tabular}{|c|c|}
\hline Course & Topics Covered \\
\hline PDD/Testing and Evaluation & $\begin{array}{l}\text { - Skills and confidence for the PDD (academic writing) } \\
\text { - Basic concepts in testing (criteria, rubrics, etc.) } \\
\text { - A wide array of adaptable options for testing }\end{array}$ \\
\hline Pedagogical Tools & $\begin{array}{l}\text { For teachers to become more aware of other ways of } \\
\text { teaching in order to make informed choices } \\
\text { To suggest a variety of teaching options and discuss which } \\
\text { would be valid in different situations (audiolingual, CLT, } \\
\text { task-based learning, etc.) }\end{array}$ \\
\hline Multimedia Tools & $\begin{array}{l}\text { - To examine a variety of resources related to multimedia } \\
\text { - To facilitate the development of lesson plans using } \\
\text { multimedia resources } \\
\text { - To practice using Microsoft Word and PowerPoint }\end{array}$ \\
\hline Productive Skills & $\begin{array}{l}\text { To help teachers find ways to introduce aspects of } \\
\text { Communicative Language Teaching into their classrooms } \\
\text { - To look at theories of teaching speaking and writing and } \\
\text { help teachers develop activities appropriate to their contexts }\end{array}$ \\
\hline Receptive Skills & $\begin{array}{l}\text { - To become more familiar with the } \mathrm{L} 2 \text { reading process } \\
\text { - Various approaches to teaching listening (intensive and } \\
\text { extensive) } \\
\text { - A variety of types of reading/listening activities } \\
\text { - Characteristics of successful reading exercises } \\
\text { - How to adapt reading/listening activities from ESL and EFL } \\
\text { textbooks }\end{array}$ \\
\hline
\end{tabular}

Tools (teaching methods), Multimedia Tools, Productive Skills (speaking and writing), and Receptive Skills (reading and listening). The goals of each course are summarized in Table 1.

Participants. The participants were five teachers who consented to take part in the research from the beginning of the program in Canada to the final follow-up phase of data collection. Their ages were recorded as those at the time of meeting in late August 2007. Self-selected meant that the participant applied to attend, whereas Board-selected meant that the participant was obliged to attend the program by his or her board of education. Table 2 summarizes information about the participants. As the table indicates, two of the five participants had education-related degrees. The others had degrees in linguistics or literature. The teachers had between 11 and 19 years of experience, and more than half had applied to attend the program.

Educational background, practicum, and teaching experience. Of this group, only Ms. J. and Mr. H. held undergraduate degrees in English education and thus were the only participants who had taken a number of pedagogically 
Table 2

Canadian MEXT Program Participants

\begin{tabular}{llllll}
\hline Name & Age & BADegree & $\begin{array}{l}\text { School where } \\
\text { currently teaching }\end{array}$ & $\begin{array}{l}\text { Years teaching } \\
\text { experience }\end{array}$ & $\begin{array}{l}\text { Selection to } \\
\text { Program }\end{array}$ \\
\hline Mr. T. & 41 & English Linguistics & Public academic high school & 19 & $\begin{array}{l}\text { Board-selected } \\
\text { Self-selected }\end{array}$ \\
Ms. J. & 38 & English Education & Public academic high school & 13 & Board-selected \\
Mr. H. & 37 & English Education & Public junior high school & 14 & Self-selected \\
Ms. I. & 36 & English Literature & Public junior high school & 13 & Self-selected \\
Ms. D. & 34 & English and American & Public academic high school & 11 & \\
\hline
\end{tabular}

related courses as well as more than one teaching practicum. Of all the participants, Mr. H. was the only teacher whose practicum took place in the environment in which he he envisaged working (junior high school). Mr. T., Ms. J., and Ms. D., all high school teachers, undertook their practica at the junior high school level, whereas Ms. I., a junior high school teacher, completed her practicum in a senior high school setting. Whereas Ms. I. said that her university's teaching license program had a strong influence on her current practice, the others rated their university training as having had no, little, or some influence.

Because teachers are regularly transferred among schools in their prefectures, all the teachers had taught in at least two schools and were currently teaching 13-15 classes per week with generally more than 20 students in a class. Most teachers worked with assistant language teachers (ALTs); however, some like Ms. I. worked with an ALT in the class only twice a month.

\section{Data-Collection and Analysis}

Multiple qualitative methods were used for data-collection, facilitated by the small number of participants and the longitudinal nature of the overall study. Data were collected via questionnaires (pre- and post-program) and reflection journals. Questionnaires were felt to be the best method for obtaining the language of participants, facilitating access to information, obtaining thoughtful data that participants had given attention to compiling, and providing written evidence (Cresswell, 2003). The questionnaire was also selected as an introductory data-collection device because it allowed the participants to give demographic information as well as responses to openand closed-ended questions. Some of the items on the initial pre-program questionnaire had been taken from other established questionnaires, and I had written some original items. The items from other questionnaires were used in order to compare JTEs' responses with those not only of previous MEXT program participants, but also of JTEs in general. Initial question- 
naires then allowed other collected documents such as weekly reflection journals, immediate-post-program questionnaires, six-month follow-up questionnaires, and one-year follow-up questionnaires to be compared with data initially gathered in the first pre-program questionnaire, in order to track changes in respondents' answers over time.

For this case study, I followed Cresswell's (2003) generic guide for analysis and interpretation. First, data were collected and prepared for analysis, audiorecordings were transcribed, and observations were typed from notes. Then data were read through to gain a general impression of ideas and tone, and typed cases were prepared for all participants with notes about emerging themes. Next a coding process was used to organize material into chunks (words or groups of words referring to a theme) using in vivo terms using the NVivo software program (Bringer, Johnston, \& Brackenridge, 2004). Then coding processes were used to generate a description of the people or setting as well as categories or themes for analysis. Finally, emergent themes were identified.

\section{Results and Discussion}

Results for the two junior high school teachers are presented, followed by results for the three senior high school teachers. The results at all three phases of data-collection are presented. Immediate post-program refers to the data-collection period immediately after the end of the program in Canada: six-month follow-up refers to a period approximately one Japanese school semester later; and one-year follow-up refers to the period approximately one year later. Incorporated means that JTEs reported using an activity or theory to inform their regular teaching practice. Incorporating means that JTEs reported continuing to do so. Abandoned means that they stopped doing the activity.

Junior high school teachers. Both junior high school teachers reported success in incorporating almost all of what they believed would be applicable to their teaching. The results for Mr. H. and Ms. I. are summarized in Table 3.

Mr. H. said that he had abandoned using the skimming and scanning activities he had prepared in Canada because they were too difficult for his students and also did not conform to the topics in the textbook he was required to use. Whereas Mr. H. incorporated most of his activities into his classroom practice, Ms. I. gave two of hers as homework assignments over the summer vacation: a picture diary and a self-history activity.

Both junior high school teachers, Mr. H. and Ms. I., appeared to have been successful at incorporating what they believed they could. Education and local support may have been reasons why Mr. H. reported having been able to do almost everything he thought he could. According to Wedell (2003), "the embedding of new practices in teachers' existing professional culture will not be completed solely by the provision of a single brief in-service program. Nor will any changes be embedded without appropriate readjust- 
Table 3

Results for Junior High School Teachers

\begin{tabular}{llll}
\hline & Immediate post-program & six-month follow-up & one-yearfollow-up \\
\hline Mr. H. & Writing letters & Incorporated & Incorporating \\
& Offering interesting speaking activities & Incorporated & Incorporating \\
Speech-making & Incorporated & Incorporating \\
Student-made flash cards & Incorporated & Incorporating \\
Games & Incorporated & Incorporating \\
10 criteria for effective teaching & Incorporated & Incorporating \\
CLT checklist & Incorporated & Incorporating \\
Skimming and scanning & Abandoned & \\
Activating background schema & Incorporated & Incorporating \\
\hline Ms. I. Picture diary & Incorporated & Incorporating \\
Self-history & Incorporated & Incorporating \\
Skimming and scanning & Incorporated & Incorporating \\
Test evaluation & Incorporated & Incorporating \\
Communicative activities based on & Incorporated & Incorporating \\
her textbook & Incorporated & Incorporating \\
Warm-up activities & Incorporated & Incorporating \\
\hline
\end{tabular}

ment to the processes and content of initial language teacher training" (p. 447). Perhaps because of Mr. H.'s background in education, and having taken more pedagogically related courses than almost all the other teachers in this study, he appeared to have a strong foundation on which to reinforce or build. Many times during our interviews, he reiterated that he had read much about pedagogy and CLT theory before going abroad, and even before going had already been putting into practice much of what he had (re)learned while in Canada. For example, during the six-month follow-up interview he told me that before participating in the program, he had already been doing activities to activate background schema, that he had read that activities should not take longer than 15 minutes, and that he had read much about theory in Japanese. In addition, because the lead JTE at his school had also participated in the MEXT program, he was enthusiastic about CLT and encouraged Mr. H. to bring what he had learned in Canada into his classroom.

Autonomy may have been the key to Ms. I.'s success. Although she did have to follow a mandated textbook, as the only JTE at her school she was able to use the PDD activities that she had prepared, if not in the classroom, 


\begin{tabular}{llll}
\hline & Immediate post-program & Six-month follow-up & One-yearfollow-up \\
\hline Mr. T. & Reader's Theatre & Incorporated & Abandoned \\
& Pre-reading activities & Incorporated & Abandoned \\
& Pre-writing activities & Incorporated & Abandoned \\
& Five communicative activities based on his textbook & Incorporated & Abandoned \\
& Task-based learning & Unable to incorporate & Abandoned \\
& Pair work & Incorporated & Abandoned \\
\hline Ms. J. & Sound test construction & Incorporated & Incorporating \\
& Listening cloze & Incorporated & Abandoned \\
& Pre-, while-, and post-reading activities & Incorporated & Incorporating \\
& Classroom English (TETE) & Incorporated & Abandoned \\
CALL activities & Incorporated & Incorporating \\
Rubrics for scoring oral presentations & Incorporated & Abandoned \\
Writing activities & & Incorporated \\
Ms. D. & Poster project & Incorporated & Incorporating \\
16 communicative activities related to her textbook & Abandoned & \\
Speaking test & & Incorporated \\
\hline
\end{tabular}

as summer homework. Thus she reported no obstacles to incorporating what she had learned abroad and continues to do so.

High school teachers. The picture for high school teachers is quite different from that of junior high school teachers, however. The results for Mr. T., Ms. J., and Ms. D. are summarized in Table 4.

Mr. T. hoped to try or tried many of the activities that he had prepared in Canada or hoped to use some theories to inform his practice, but after one year had abandoned everything except using pair work in his classes. After six months, Ms. J. reported being able to incorporate everything she believed she could while still in Canada; yet after one year, she reported abandoning most communicative practices from her repertoire. Ms. D. may perhaps have been the least successful at incorporating what she had learned in Canada. After six months, she reported that she had incorporated only one of the 17 communicative activities she had prepared in Canada and after one year had added a speaking test to her repertoire.

All three high school teachers had varying degrees of success in implementing CLT practices, but seemed to face more practical constraints than did junior high school teachers. This could be related to the issues that have been highlighted by other authors such as entrance examinations (Kurihara 
\& Samimy, 2007; Sakui, 2004; Sato \& Kleinsasser, 2004), mandated textbooks (Gorsuch, 1999), and student/teacher factors (Lamie, 2001).

\section{Entrance Examinations}

All three teachers linked their abandonment of CLT practices to the preparation of their students for university entrance examinations. Ms. D. explicitly stated, "I always have ideas for activities, but when I think about the entrance examination, I often choose not to put the ideas into practice." This may be a good example of what Beauchamp and Vardaman (1994) refer to as a distortion effect on pre-tertiary level schools. According to them,

The whole school system, particularly at the higher secondary level, runs the danger of being turned into a cram system for the entrance examinations and distracted from its true educational objectives.

Curricula are shaped to meet the examination requirements rather than the needs of students in terms of their current levels of maturation and their future educational and career needs. (p. 208)

Thus given the importance of the entrance examination in the Japanese educational system, it is not surprising that the senior high school teachers placed examination success at the forefront of their teaching considerations.

\section{Textbooks/Courses}

In a similar vein, the selection of textbooks (which is highly regulated in the Japanese schooling system) has also proven to be an area of concern for JTEs trying to incorporate communicative activities into their teaching. Both Mr. T. and Ms. D. mentioned that their textbooks affected their ability to use CLT in their classes. Mr. T. felt that he needed to keep pace with his colleagues and cover textbook topics at the same rate; he believed that he could not introduce any activities that were unrelated to the textbook. This is consistent with other research that has found that the curriculum focuses on textbooks and the strict implementation of timetables relating to these books (Gorsuch, 1999). In many high schools, the existence of a timetable for textbooks is consistent with the pressure that Mr. T. indicates he felt in relation to this. Similarly, Ms. D. also stated concerns regarding the textbooks that she was using. Having moved to a new school immediately after being accepted to participate in the MEXT program, she brought a textbook with her as requested, but it was not the one that she would be using at her new school. Thus the activities that she had prepared based on the old textbook were no longer useful to her. Ms. J. had incorporated a number of CLT activities, but had been doing them in an oral communication class, the venue where she felt it was best to complete them. However, once this course finished and she began teaching third-year students and preparing them for entrance examinations, she abandoned such activities. 
Unlike in Canada where teachers may have some freedom in textbook selection, in Japan, "all public school students receive the same education based on almost identical textbooks and a shared curriculum ... teachers deliver knowledge of academic subjects through textbook-centered class instruction" (Ishikida, 2005, pp. 58-59). Thus textbooks significantly constrain the amount of CLT that JTEs can incorporate into their teaching practice.

\section{Student factors/Teacher factors}

Another issue raised by the JTEs was related to the relationship between student and teacher in the classroom. The dynamic in a Japanese classroom may be somewhat different from that in a Canadian classroom, as teachers are often considered to be the leader of the group, the one who talks while the students listen. The nature of the communicative classroom is such that both teachers and students interact more freely to facilitate discussion and communication, and this can sometimes be a constraint faced by teachers conducting a classroom in a traditional way. This was clearly an issue for Mr. T., who indicated that he abandoned conducting activities in English because his students were silent, which meant that he could not gauge the extent of their understanding. When asked to offer more detail about what he felt to be an unusually quiet group, Mr. T. said that although their test scores were high, and although his school tended to admit the best students in the area, this particular class tended not to react or interact at all, even when asked to respond individually. Although such students probably had sufficient language skills to comprehend and respond in class, they may have been choosing to resist the new methodology. This issue also resonated with Ms. D., who indicated that because she had been transferred just before attending the MEXT program, she did not know her students well enough to design activities tailored to their needs.

An additional problem that has been highlighted in other research (Lamie, 2001; Li, 1998, 2001) is teachers' belief in their own proficiency in English. Mr. T. indicated that he believed that his own English proficiency was not sufficient for doing task-based learning. Confidence is an issue that also appears to constrain many teachers, particularly in terms of limiting their desire to interact in English. As this interaction is the basis of the CLT activities being introduced in the MEXT program, this could prove a largely limiting factor.

\section{Conclusions and Implications}

The findings of this study highlight that although teachers were ultimately able to put into practice some of what they learned abroad, a number of practical constraints-particularly entrance examination pressures, mandated textbooks, autonomy issues, and student and teacher factors-ap- 
peared to continue to obstruct third-year public high school JTEs from incorporating CLT practices into their classrooms. Because, depending on the school, teachers may ultimately teach all levels of students, it is necessary that these constraints be taken into consideration at inservice program planning stages to help ensure that all teachers are able to make the best use of their overseas study period.

One way to do this would be for program planners and instructors to be familiar with the various types of entrance examinations in Japan in order to help JTEs find communicative ways of helping students prepare for them. This may not be easy, because while JTEs are preparing students, they are required to use mandated textbooks and may feel pressure to work at the same pace as their colleagues. However, familiarity with a variety of Japanese entrance examinations is recommended for host country personnel; entrance examination success is the main reason most Japanese students study English. If host personnel can help JTEs make the link between CLT and entrance examination success, there may be a greater chance that JTEs will adopt such practices more readily.

Regarding mandated textbooks, program planners and instructors might bear in mind that textbooks change every few years or, as in Ms. D.'s case, may change suddenly if the teacher is transferred to a new school. Perhaps in addition to helping JTEs prepare activities based on their current texts, they might also learn how to create activities based on any possible text that the teacher may be obliged to use. However, because third-year instructors have limited preparation time, it is important that creation of activities should be neither time- nor resource-consuming.

The following checklist, although not exhaustive, may be helpful for future INSET programs sponsored by MEXT and designed for Japanese teachers of English. With regard to CLT activities, these

- should take less than 10 minutes to prepare;

- should take less than 10 minutes to execute;

- should not depend on audiovisual or other media;

- should not necessitate colleagues' consensus;

- should be nonthreatening to classroom harmony; and

- should not necessarily demand that students display knowledge.

It may also be helpful for JTEs to be shown strategies for creating participative and inclusive classrooms, and if possible to be given opportunities to practice activities with as similar a group of students as possible if there is a Japanese school for children of diplomats or businesspeople in the area.

Finally, it is important to keep in mind that JTEs' practices are positively affected by the program and that given the right conditions, they will be able to incorporate new practices into their English classrooms at some point. From 2011, English will be compulsory at the elementary school level (Torikai, 2009). Although English will not be taught as other regular subjects 
are-compared with other subjects such as mathematics, the teachers will not necessarily be specialists in English-language teaching, and there will be no mandated textbooks or numerical grading - the idea of introducing it is to "plant the seeds within the students for developing communicative competence" (Torikai, p. 1). Elementary school teachers may be those who might reap the most benefit from overseas INSET programs; perhaps MEXT will begin sponsoring them in the near future.

\section{The Author}

Melodie Cook is an associate professor in the University of Niigata Prefecture, Niigata, Japan. She recently completed her doctorate in applied linguistics at Macquarie University, Australia. Her research interest is in language-teacher training in Japan.

\section{References}

Aspinall, R.W. (2003). Nationalism and the reform of English language teaching. In R. Goodman \& D. Phillips (Eds.), Can the Japanese change their education system? (pp. 103-117). Oxford, UK: Oxford University Press.

Beauchamp, E.R., \& Vardaman, Jr., J.M. (Eds.). (1994). Japanese education since 1945: A documentary study. Armonk, NY: M.E. Sharpe.

Blumenthal, T. (1992). Japan's Juken industry. Asian Survey, 32(5), 448-460.

Bogdan, R.C., \& Biklen, S.K. (2007). Qualitative research for education: An introduction to theories and methods. Boston, MA: Pearson.

Bringer, J.D., Johnston, L.H., \& Brackenridge, C.H. (2004). Maximizing transparency in a doctoral thesis: The complexities of writing about the use of QSR*NVIVO within a grounded theory study. Qualitative Research, 4(2), 247-265.

Browne, C.M., \& Wada, M. (1998). Current issues in high school English teaching in Japan: An exploratory survey. Language, Culture and Curriculum, 11(1), 97-112.

Cresswell, J.W. (2003). Research design: Qualitative, quantitative, and mixed methods approaches. Thousand Oaks, CA: Sage.

Department, N.H.S.E. (2009). English Department schedule of learning and evaluation (Eigoka gakushuuto hyoukanokeikakuhyou). In-house high school publication.

Gorsuch, G.J. (1999). Monbusho approved textbooks in Japanese high school EFL Classes: An aid or a hindrance to educational policy innovations? Language Teacher, 23(10), 5-15.

Gorsuch, G.J. (2001). Japanese EFL teachers' perceptions of communicative, audiolingual and yakudoku activities: The plan versus the reality. Educational Policy Archives, 9(10). Retrieved July 21, 2010, from: http:/ /epaa.asu.edu/epaa/v9n10.html

Hawley, C.A., \& Hawley, W.D. (1997). The role of universities in the education of Japanese teachers: A distant perspective. Peabody Journal of Education, 72(1), 233-244.

Hino, N. (1988). Yakudoku: Japan's dominant tradition in foreign language learning. JALT Journal, 10(1, 2), 45-55.

Ishikida, M.Y. (2005). Japanese education in the 21st century. New York: Universe.

Kamiya, S. (2009, January). “Exam hell” now not so hot. Japan Times Online. Retrieved December 22, 2009, from: http://search.japantimes.co.jp/cgi-bin/nn20090120i1.html

Kikuchi, K. (2006). Revising English entrance examinations at Japanese universities after a decade. JALT Journal, 28(1), 77-96.

Kurihara, Y., \& Samimy, K.K. (2007). The impact of a U.S. teacher training program on teaching beliefs and practices: A case study of secondary school level Japanese teachers of English. JALT Journal, 29(1), 99-122.

Lamie, J.M. (2000). Teachers of English in Japan: Professional development and training at a crossroads. JALT Journal, 22(1), 27-45. 
Lamie, J.M. (2001). Understanding change: The impact of in-service training on teachers of English in Japan. New York: Nova Science.

Langham, C. (2007). MEXT-authorized English textbooks: The writing and screening of a Japanese high school text series. Paper presented at the 6th annual JALT Pan-SIG conference, Sendai, Japan, Tohoku Bunka Gakuen University.

Li, D. (1998). "It's always more difficult than you plan and imagine": Teachers' perceived difficulties in introducing the communicative approach in South Korea. TESOL Quarterly, $32,677-703$.

$\mathrm{Li}, \mathrm{D}$. (2001). Teachers' perceived difficulties in introducing the communicative approach in South Korea. In D.R. Hall \& A. Hewings (Eds.), Innovation in English language teaching: A reader (pp. 149-168). London: Routledge.

Matsumoto, K. (1994). English instruction problems in Japanese schools and higher education. Journal of Asian Pacific Communication, 5(4), 209-214.

McVeigh, B.J. (2002). Japanese higher education as myth. New York: M.E. Sharpe.

McVeigh, B.J. (2006). The state bearing gifts: Deception and disaffection in Japanese higher education. New York: Lexington.

Ministry of Education, Culture, Sports, Science and Technology_Japan. (2003). Regarding the establishment of an action plan to cultivate "Japanese with English abilities." Retrieved July 20, 2010, from: http:/ / www.mext.go.jp/english/topics/03072801.htm

Nagasawa, K. (2004). Teacher training and development. In V. Makarova \& T. Rodgers (Eds.), English language teaching: The case of Japan. Munich: Lincom Europa.

O'Donnell, K. (2005). Japanese secondary English teachers: Negotiation of educational roles in the face of curricular reform. Language, Culture and Curriculum, 18(3), 300-315.

Okano, K., \& Tsuchiya, M. (1999). Education in contemporary Japan: Inequality and diversity. Cambridge, UK: Cambridge University Press.

Otsu, T. (2004). The unified test by the NCUEE-It's role in Japanese university admissions. Paper presented at the international educational examination forum, Tianjin.

Pacek, D. (1996). Lessons to be learnt from negative evaluation. ELT Journal, 50(4), 335-343.

Rohlen, T.P. (1980). The juku phenonmenon: An exploratory essay. Journal of Japanese Studies, $6(2), 207-242$.

Sakui, K. (2004). Wearing two pairs of shoes: Language teaching in Japan. ELT Journal, 58(2), 155-163.

Sato, K., \& Kleinsasser, R.C. (2004). Beliefs, practices, and interactions of teachers in a Japanese high school English department. Teaching and Teacher Education, 20, 797-816.

Sato, M., \& Asanuma, S. (2000). Japan. In P. Morris \& J. Williamson (Eds.), Teacher education in the Asia-Pacific region: A comparative study (pp. 107-131). New York: Falmer Press.

Torikai, K. (2009, May 5). Seeds of English learning/Primary classes aim is for children to enjoy language. Retrieved July 10, 2010, from:

http://educationinjapan.wordpress.com/edu-news/latest-changes-in-english-education/

Tsukada, M. (1988). Institutionalized supplementary education in Japan: The Yobiko and Ronin student adaptations. Comparative Education, 24(3), 285-303.

Wedell, M. (2003). Giving TESOL change a chance: Supporting key players in the curriculum change process. System, 31, 439-456.

Yashima, T., Zenuk-Nishide, L., \& Shimizu, K. (2004). The influence of attitudes and affect on willingness to communicate and second language communication. Language Learning, 54(1), 119-152.

Yonesaka, S. (1999). The pre-service training of Japanese teachers of English. Language Teacher, 23(11). Retrieved July 1, 2010, from: http://www.jalt-publications.org/tlt/articles/1999/11/yonesaka 